\title{
Anatomical observation and significance of the parietal foramen in Chinese adults
}

\author{
D. $\mathrm{Liu}^{1}{ }^{1 *}, \mathrm{H}$. Yang ${ }^{1 *}$, J. Wu ${ }^{2 *}$, J.-H. Li ${ }^{1}$, Y.-K. Li ${ }^{1}$ \\ 'School of Traditional Chinese Medicine, Southern Medical University, Guangzhou, Guangdong, P.R. China \\ 2Department of Rehabilitation Medicine, the third affiliated Hospital, Southern Medical University, Guangzhou, \\ Guangdong, P.R. China
}

[Received: 19 September 2021; Accepted: 3 October 2021; Early publication date: 21 October 2021]

Background: This study aimed to investigate the incidence, number, diameter, and relative location of the parietal foramen (PF) as well as communication of intracranial and extracranial orifices and their direction, and sagittal suture morphology and length.

Materials and methods: A total of 280 dry Chinese adult skull specimens from the Department of Anatomy, Southern Medical University, were observed and measured. The occurrence rate and quantity of the $P F$ near the sagittal suture were recorded. The aperture of the PF, the vertical distance between PF and sagittal suture, and the linear distance between PF and lambda were measured using a Vernier calliper. The length of the sagittal suture was measured by a flexible ruler; the direction and communication of intracranial and extracranial orifices were detected using a probe.

Results: The total incidence of the PF was $82.86 \%$, slightly higher on the right side than on the left side. The single-foramen type was the most prevalent. The mean diameter of the PF on the left and right sides were $1.02 \pm 0.72 \mathrm{~mm}$ and $1.07 \pm 0.67 \mathrm{~mm}$, respectively, and the diameter of the PF on the sagittal suture was $1.77 \pm 0.44 \mathrm{~mm}$. The mean vertical distance between the PF and the sagittal suture was $5.90 \pm 2.78 \mathrm{~mm}$ and $5.85 \pm 2.75 \mathrm{~mm}$ on the left and right sides, respectively. The shape of the sagittal suture in the PF area was primarily dentate shaped, with an average arc length of $\chi=124.36 \pm 7.76 \mathrm{~mm}$, of which the majority were completely healed type. The intracranial and extracranial communication was 39.97\%, and the majority of the PF were anteromedial direction.

Conclusions: The current study provided an anatomical basis for imaging diagnosis and neurosurgery by investigating the incidence, diameter, and relative location of the PF and intracranial and extracranial communication and direction. (Folia Morphol 2022; 81, 4: 998-1004)

Key words: anatomy, skull, parietal foramen, sagittal suture, lambda, parietal emissary vein 


\section{INTRODUCTION}

The parietal foramen (PF) is a small inconsistent diameter opening located at the border of the middle $1 / 3$ and posterior $1 / 3$ of the parietal bone near the sagittal suture. It is usually considered an emissary foramen [19]. The edge of the PF is clear, with meningeal branches of the occipital artery, venules and nerves passing through [13]. PF has some important functions, such as communicating intracranial and extracranial transmitting blood vessels, nerves, and regulating intracranial pressure and body temperature, while it remains unclear whether the PF has other functions $[5,11]$. The anatomical knowledge of the $\mathrm{PF}$ is essential for neurosurgery because surgical manoeuvres may rupture the guiding vein and thus lead to bleeding. Moreover, intracranial navigation through the PF for vascular disease (e.g. dural arteriovenous fistulas) is becoming mainstream research [18, 22].

The existing literature has shown that the incidence, number, diameter, shape, relative location of the $P F$, and intracranial and extracranial communication and direction are not constant $[19,23]$. There are few studies investigating this topic on the Asian race to date, especially Chinese. The current study aimed to observe and provide a large number of anatomical data related to the PF in Chinese adults, to review the frequency and diameter of the PF in different ethnic groups, and to provide an anatomical reference for clinical, scientific research and teaching of modern medicine.

\section{MATERIALS AND METHODS}

\section{Materials and instruments}

A total of 280 dry Chinese adult skull specimens from the Department of Anatomy, Southern Medical University, were observed and measured after excluding skull damage, lesions, malformations, and intracranial foreign body filling. All the specimens were treated by corrosion, cleaning and drying. The structures were complete, and the external conditions of the skull, such as the PF and sagittal suture, were clearly identified. The sex of the specimens was known, but no age identification was made.

\section{Methods}

The incidence and number of the PF were observed by visual inspection, and the diameter of the PF, the vertical distance between the PF and the sagittal suture, and the linear distance between the PF and the herringbone were measured using a digital Vernier calliper with an accuracy of $0.01 \mathrm{~mm}$ (Wuxi Kaibaoding Tools Co., Ltd., China). The length of the sagittal suture (the arch from the bregma [b] to the lambda [l]) was measured using a flexible ruler. The direction and communication of intracranial and extracranial orifices were detected using a probe with a diameter of $0.5 \mathrm{~mm}$.

All the above items were measured 3 times independently by 2 researchers. Both researchers had more than 2 years of experience in anatomical measurements and were trained before the measurement to reduce systematic errors. After the measurement, the digital image acquisition (D610 camera, Nikon) and image processing (Photoshop 2020, Illustrator 2020, Adobe) were performed.

All methods in the current study complied with the Declaration of Helsinki. The study was approved by the Chinese Ethics Committee of Registering Clinical Trials (Reference No. ChiECRCT20210191).

\section{Statistical analysis}

IBM SPSS Statistics for Windows 26.0 was used to analyse statistics. The values are expressed as an mean \pm standard deviation $(\bar{\chi} \pm s)$. The Kolmogorov-Smirnov test was used to assess the normality of the data. The paired-sample t-test or Wilcoxon signed-rank test was used to assess bilateral asymmetry, and an independent-sample t-test or Mann-Whitney $U$ test was used to assess gender dimorphism. For all the analyses, $\mathrm{p}<0.05$ was considered to indicate statistical significance.

\section{The incidence of the PF}

\section{RESULTS}

Of the 280 skulls measured, 161 were males, and 119 were females, with a male-to-female ratio of $1.35: 1$. The overall incidence of PF was $82.86 \%$ (232/280). Among the PFs, the incidence of the left PF was $63.21 \%(177 / 280)$, the incidence of the right PF was $66.07 \%$, and the incidence of simultaneous incidence was $48.93 \%$ (137/280). Additionally, the incidence of the PF on the sagittal suture was $2.5 \%$ (7/280) (Fig. 1). These incidences of the PF were compared with findings of previous studies (Table 1) $[2,3,5,7,9,14,18,31,32]$.

\section{The diameter of the PF}

The diameters of the PF on the left and right sides were $1.02 \pm 0.72 \mathrm{~mm}$ and $1.07 \pm 0.67 \mathrm{~mm}$, respectively, and the diameter of the PF on the sagittal suture was $1.77 \pm 0.44 \mathrm{~mm}$. The diameters of 


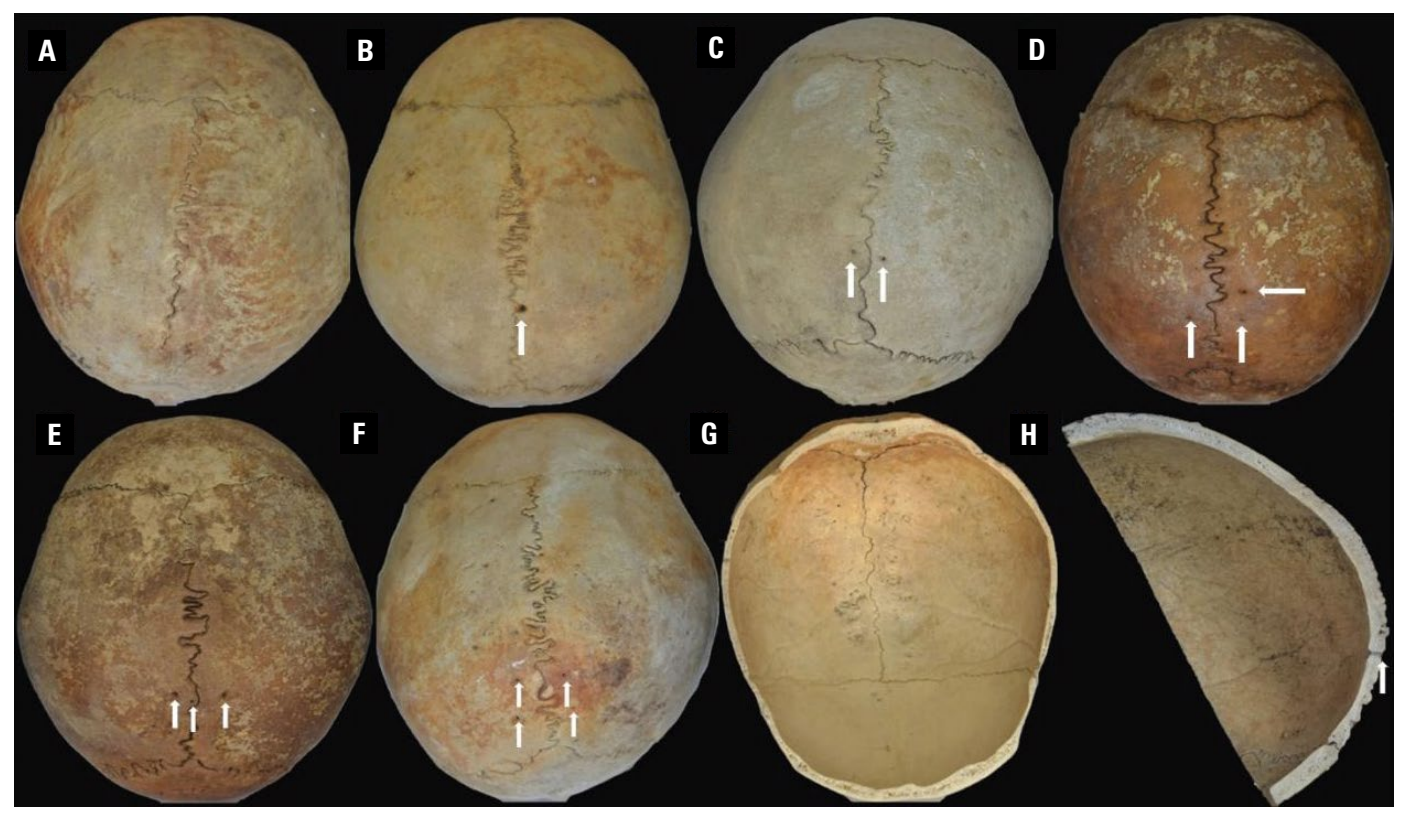

Figure 1. Presence/absence of the parietal foramen (PF); A. Absent; B. Present unilaterally (arrow); C. Present bilateral (arrow); D-F. Presence of multiple foramina (arrows); G. Internal view of the PF; H. Sagittal section in the PF.

Table 1. Incidence of the parietal foramen (from high to low incidence)

\begin{tabular}{|c|c|c|c|c|c|}
\hline No. & Author (s) & Year & Population & $\begin{array}{l}\text { Sample } \\
\text { size (n) }\end{array}$ & $\begin{array}{c}\text { Incidence } \\
(\%)\end{array}$ \\
\hline 1 & $\begin{array}{l}\text { de Souza Ferreira } \\
\text { et al. [5] }\end{array}$ & 2021 & Brazil & 301 & 84.3 \\
\hline 2 & Present study & 2021 & Chinese & 280 & 82.86 \\
\hline 3 & Mann et al. [14] & 2009 & Japan & 137 & 80.3 \\
\hline 4 & Gangmei [7] & 2018 & India & 48 & 77.1 \\
\hline 5 & $\begin{array}{c}\text { Murlimanju et al. } \\
{[18]}\end{array}$ & 2015 & $\begin{array}{l}\text { South } \\
\text { Indians }\end{array}$ & 116 & 71.5 \\
\hline 6 & Keskil et al. [9] & 2003 & Turkey & 200 & 63 \\
\hline \multirow[t]{8}{*}{7} & $\begin{array}{l}\text { Carolineberry } \\
\text { and Berry [3] }\end{array}$ & 1967 & $\begin{array}{l}\text { North } \\
\text { America }\end{array}$ & 50 & 62 \\
\hline & & & Nigeria & 56 & 59.2 \\
\hline & & & Peru & 53 & 53 \\
\hline & & & India & 53 & 50 \\
\hline & & & Burma & 51 & 50 \\
\hline & & & Egypt & 250 & 44.2 \\
\hline & & & $\begin{array}{l}\text { Palestine } \\
\text { (Lachish) }\end{array}$ & 54 & 35.2 \\
\hline & & & $\begin{array}{l}\text { Palestine } \\
\text { (Modern) }\end{array}$ & 18 & 22.2 \\
\hline 8 & Boyd [2] & 1930 & Scotland & 1500 & 60 \\
\hline 9 & $\begin{array}{c}\text { Wysocki et al. } \\
\text { [31] }\end{array}$ & 2006 & Poland & 100 & 60 \\
\hline 10 & $\begin{array}{c}\text { Yoshioka et al. } \\
\text { [32] }\end{array}$ & 2006 & USA & 20 & 50 \\
\hline
\end{tabular}

Table 2. Diameter of the parietal foramen [mm]

\begin{tabular}{lcccc}
\hline \multirow{2}{*}{$\begin{array}{l}\text { Bore } \\
\text { diameter }\end{array}$} & \multicolumn{2}{c}{ Side } & \multicolumn{2}{c}{ Gender } \\
\cline { 2 - 5 } & Left & Right & Males & Females \\
\hline Minimum & 0 & 0 & 0 & 0 \\
Maximum & 3.29 & 2.82 & 3.29 & 2.82 \\
Mean \pm SD & $1.02 \pm 0.72$ & $1.07 \pm 0.67$ & $1.05 \pm 0.71$ & $1.07 \pm 0.69$ \\
$P$ & \multicolumn{2}{c}{$>0.05$} & \multicolumn{2}{c}{$>0.05$} \\
\hline SD - standard deviation & &
\end{tabular}

the PF in males and females were $1.05 \pm 0.71 \mathrm{~mm}$ and $1.07 \pm 0.69 \mathrm{~mm}$, respectively, and there was no statistically significant difference in the diameter of the PF in sides and sex ( $p>0.05)$ (Table 2).

\section{The relative location of the PF}

The vertical distance between the PF and the sagittal suture was $6.12 \pm 2.62 \mathrm{~mm}$ and $5.96 \pm$ $2.60 \mathrm{~mm}$ on the left and right sides, respectively. The vertical distance between the PF and the sagittal suture was not statistically different in sides and sex ( $p>0.05)$.

The linear distance between the PF and the lambda was $35.33 \pm 6.36 \mathrm{~mm}$ and $34.27 \pm 5.84 \mathrm{~mm}$ on the left and right sides, respectively; $34.90 \pm 6.50 \mathrm{~mm}$ and $34.40 \pm 5.98 \mathrm{~mm}$ in males and females, respectively. The distance between the PF to the lambda was not statistically different between sexes $(p>0.05)$ 
Table 3. The vertical distance between the parietal foramen (PF) and the sagittal suture and the linear distance between the PF and the lambda $[\mathrm{mm}]$

\begin{tabular}{|c|c|c|c|c|c|c|c|c|}
\hline \multirow[t]{3}{*}{ Distance } & \multicolumn{4}{|c|}{ Sagittal suture } & \multicolumn{4}{|c|}{ Herringbone } \\
\hline & \multicolumn{2}{|c|}{ Side } & \multicolumn{2}{|c|}{ Gender } & \multicolumn{2}{|c|}{ Side } & \multicolumn{2}{|c|}{ Gender } \\
\hline & Left & Right & Males & Females & Left & Right & Males & Females \\
\hline Minimum & 0 & 0 & 0 & 0.81 & 12.22 & 17.79 & 12.22 & 20.08 \\
\hline Maximum & 13.84 & 15.09 & 15.09 & 12.06 & 46.46 & 52.94 & 48.49 & 52.94 \\
\hline Mean \pm SD & $6.12 \pm 2.62$ & $5.96 \pm 2.60$ & $6.18 \pm 2.94$ & $5.98 \pm 2.33$ & $35.33 \pm 6.36$ & $34.27 \pm 5.84$ & $34.90 \pm 6.50$ & $34.40 \pm 5.98$ \\
\hline$P$ & \multicolumn{2}{|c|}{$>0.05$} & \multicolumn{2}{|c|}{$>0.05$} & \multicolumn{2}{|c|}{$<0.001$} & \multicolumn{2}{|c|}{$>0.05$} \\
\hline
\end{tabular}

SD — standard deviation

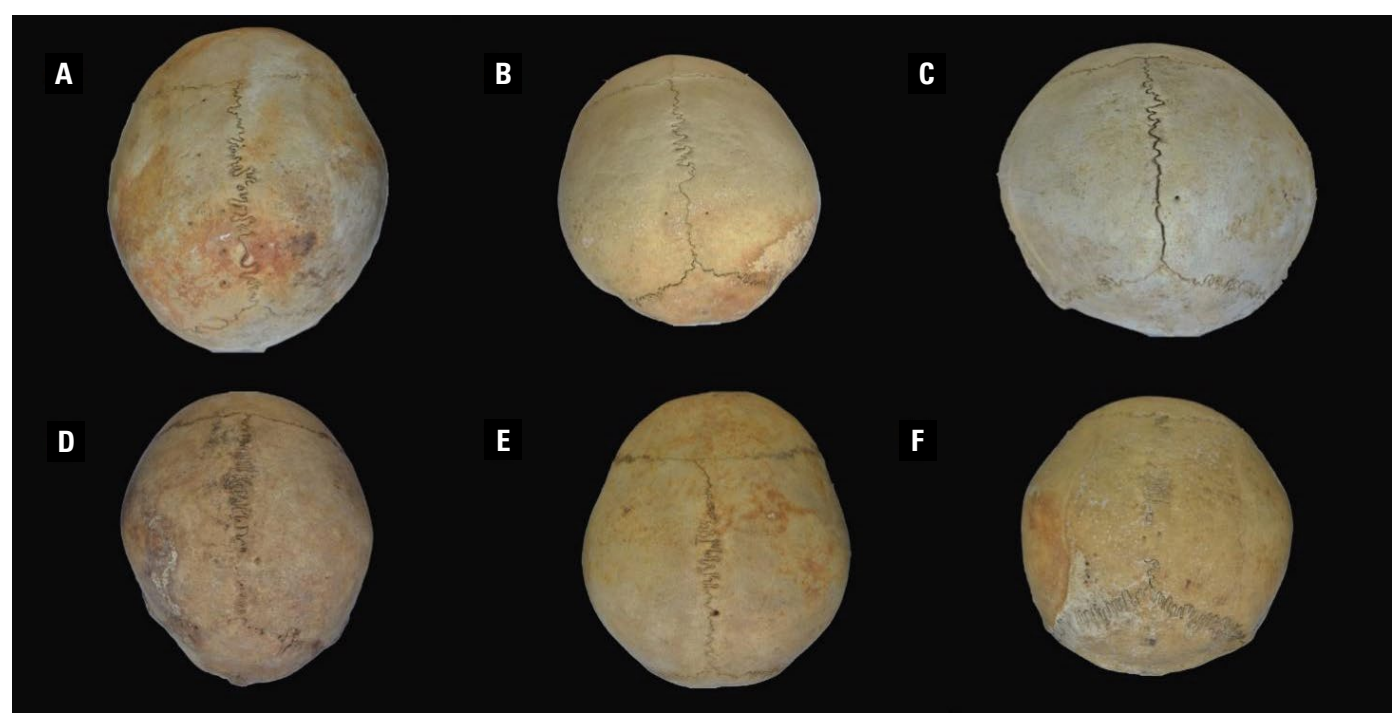

Figure 2. The shape of the extracranial sagittal suture; A. Dentate suture; B. Corrugated suture; C. Straight suture; D. Healed suture; E. Secondary corrugated suture; $\mathbf{F}$. The secondary healed suture.

but was slightly longer on the left side than on the right side $(p<0.001)$ (Table 3).

The shape distribution, length and degree of healing of the extracranial sagittal suture

The configuration of the human cranial suture is similar to a fingerprints, which differ from each other, and the morphology of the cranial suture is complex and highly specific [2]. The shape of the extracranial sagittal suture in the interparietal foramen area could be divided into six types: straight suture in $3(1.04 \%)$ cases; dentate suture in 222 (79.27\%) cases; the corrugated suture in $44(15.54 \%)$ cases; the secondary corrugated suture in $4(1.55 \%)$ cases; healed suture in $4(1.55 \%)$ cases; the secondary healed suture in $4(1.55 \%)$ cases (Fig. 2$)$. The arc length of the sagittal suture was between $100 \mathrm{~mm}$ and $141 \mathrm{~mm}(\chi=124.36 \pm$ $\pm 7.76 \mathrm{~mm}$ ) (Table 4). $66.22 \%$ of the extracranial sagittal sutures were completely healed, $31.08 \%$
Table 4. Range and proportion of arc length of the sagittal suture $(\mathrm{n}=280)$

\begin{tabular}{lccccc}
\hline Range [mm] & $100-109$ & $110-119$ & $120-129$ & $130-139$ & $\geq 140$ \\
Percentage & $2.78 \%$ & $18.05 \%$ & $51.39 \%$ & $26.39 \%$ & $1.39 \%$ \\
\hline
\end{tabular}

were partially healed, and $2.70 \%$ were completely unhealed.

\section{The intracranial and extracranial communication} of the PF

Of the 280 skulls measured, a total of 98 skulls with 178 PF had intracranial and extracranial communication. Among these PF, the communication rate of the PF on the left and right sides was $17.18 \%$ (48 cases) and $22.09 \%$ (63 cases), respectively. The incidence of the PF communication on both sides was $6.75 \%$ ( 20 cases), and the PF communication on the sagittal suture was $2.45 \%$ ( 7 cases). The PF commu- 
nication was found in $19.64 \%$ (55 cases) in males and $15.36 \%$ (43 cases) in females. Intracranial and extracranial communication of the PF was not statistically different between sides and sexes $(p>0.05)$.

The 178 single-hole PF were classified according to their directions [8]: $39.70 \%$ (46) antero-medial direction, $17.65 \%$ (21) anterior direction, $13.24 \%$ (15) antero-lateral direction, $13.24 \%$ (15) antero-superior direction, $11.76 \%$ (14) antero-inferior direction, $2.94 \%$ (3) medio-superior direction, and $1.47 \%$ (2) medio-inferior direction.

\section{DISCUSSION}

The PF is usually located on both sides of the middle $1 / 3$ and posterior $1 / 3$ of the sagittal suture [19]. The frequency, number, diameter, shape, location of the $P F$, intracranial and extracranial communication and direction are not constant. Studying the PF is, therefore, important not only for understanding the complex regional neurovascular anatomy but also for distinguishing between normal and potentially abnormal structures [26].

The overall incidence of the PF measured in the current study was $82.86 \%$, which was different from other populations (Table 1), which may be due to ethnic differences, and this trend was also reported by Makandar et al. [12]. With the development of imaging technology, the diameter of the PF can be scanned by magnetic resonance imaging and computed tomography to diagnose some diseases, so it is of considerable significance for research on the diameter of the PF. The diameter of the PF in Chinese adults measured in this study was larger than that in the study by Yoshioka et al. [32] but smaller than that in the study by Carolineberry and Berry [3] and Singh and Raibagkar [24], and the diameter was not statistically different between sides and sexes $(p>0.05)$. The distance between the PF and the sagittal suture can affect the complexity of the sagittal suture, and the mean distance was $5.90 \pm 2.78 \mathrm{~mm}$ on the left side and $5.85 \pm 2.75 \mathrm{~mm}$ on the right side, which was smaller than $6.7 \mathrm{~mm}$ reported by Murlimanju et al. [19]. Investigating the specificity of cranial sutures, especially extracranial sagittal sutures, may provide a new way of identifying individual biological information for criminal investigation, forensics and other fields.

The PF is a characteristic of humans, which is less frequent in lower animals and absent in some species [2]. Normal PF usually transmits venules connecting the occipital vein and superior sagittal sinus, anastomosis and nerves between the middle meningeal artery and occipital artery [26]. Reis et al. [22] studied 40 parietal regions in 20 adult bodies and observed that each foramen transmitted an anastomotic vessel between the middle meningeal artery and the extracranial artery, with the superficial temporal artery anastomosing with the superficial occipital artery in $55 \%$ of cases and the middle meningeal artery anastomosing with the pericranial arteriole in the remaining cases (45\%) [22]. The emissary vein (EV) in the PF crosses the skull with varying degrees of inclination, while presenting a highly consistent course on the sagittal plane [26].

Other functions of the PF (except allowing vessels to pass through) remain unknown and under ongoing investigation. In the study by Tsutsumi et al. [26], it was found that $75 \%$ of the EVs passed through the PF as a single channel. EV could function as a blood supply vessel under pathological conditions; for example, EV could play a role in supplying dural vessels in the case of maxillary sinus dural arteriovenous fistulas, and EV could be found to play a role in supplying blood in magnetic resonance imaging of patients with parasagittal meningiomas [26]. The EVs drain intracranial and extracranial blood flow. These veins are not valvular and play a key role in controlling intracranial pressure and body temperature, particularly when the head position and Valsalva manoeuvre changes during daily physical activity [16]. Boyd [2] also proposed that the skull roof osteomyelitis, meningitis, and brain abscess may be complications due to perforating vein infection between the diploe, meninges, and meningeal veins, and then concluded that scalp injury and disease would be reduced by half without the EV [2]. Additionally, Chapot et al. [4] reported firstly several cases of dural fistula treated by transcranial puncture of the PF and the mastoid foramen. The arterial anastomosis in the dural fistula was enlarged and supplied to the vessels of the PF and mastoid foramen, and the intracranial segment of the supply artery was traversed along a straight line [4]. The PF or mastoid foramen, therefore, could be directly punctured and entered into the straight segment of the supply artery, and propylene glue could be injected to embolise the fistula [4].

There are scarce studies on the role of nerves in the PF to date. Lacković et al. [10] found that there may be a direct bidirectional innervation between 
the trigeminal nerve in the parietal foramen and the epidural system through the experiment of botulinum toxin in the treatment of migraine in mice [10].

Enlarged parietal foramina (EPF) are rare defects in parietal bone development resulting from intramembranous osteogenesis abnormalities, and they are not homologous to normal PF and have a different development basis [1, 20, 28]. It was first described in 1707 but not appreciated by scholars until the 1940s [8]. During the development of a normal foetus, intramembranous osteogenesis occurs in the squamous portion of the frontal, parietal, and temporal bones, which are usually ossified during the $5^{\text {th }}$ month of gestation. When there is insufficient ossification around the parietal notch, they form giant permanent holes [8]. The diameter has been reported to be up to $2.0 \mathrm{~cm}$ [25], and the incidence is not well understood. Tubbs et al. [27] reported its incidence to be about 1 in 15,000 to 1 in 25,000 , and transmission by autosomal dominant inheritance. The EPF is associated with Saethre-Chotzen syndrome [25] and the deletion of chromosome 11 [1]. The EPF is now thought to result from mutations in the homeobox genes ALX4 (located on chromosome 11) and MSX2 (located on chromosome 5) [15, 29, 30]. Therefore, Durão et al. [6] proposed that decreased identity information could be clarified by forensic identification based on rare anatomical variations of the PF. In addition, studies have found that pathological processes of some diseases may change the diameter and shape of the skull foramina, which may be associated with cranial malformation, cleft lip and palate, craniofacial dysplasia, broad thumb syndrome, hypoplasia of the skull and clavicle, and syndrome consisting of the hypoplastic syndrome [17, 21], ocular inflammation, hyperglycaemia, obesity, mental retardation and epilepsy [27]. The treatment of the EPF is usually conservative; traditional Chinese medical massage and acupuncture can change intracranial and extracranial, and diploic vascular blood flow, but whether the treatment could change the diameter of the PF remains unclear. However, persistent cranioschisis may require surgical closure [8]. In the current study, the EPF was not observed.

\section{Limitations and expectations}

This study had some limitations, e.g. no geographical and age analysis and identification. Also, the relevant data of the PF were measured and analysed manually in this study, and advanced instruments and equipment such as computer analysis were not used. For future research, modern instruments and equipment can be used to carry out more in-depth and precise research on clinical anatomy to obtain more anatomical information conducive to basic and clinical medicine.

\section{CONCLUSIONS}

This study measured the incidence, diameter, and location of the PF in Chinese adults, and found the differences compared with other ethnic groups. These findings also provided us with a scientific basis for imaging diagnosis and treatment associated with the PF.

\section{Acknowledgements}

We are grateful to the Human Anatomy Laboratory of the Southern Medical University, which provided materials that were essential to carry out the study.

\section{Conflict of interest: None declared}

\section{REFERENCES}

1. Bartsch O, Wuyts W, Van Hul W, et al. Delineation of a contiguous gene syndrome with multiple exostoses, enlarged parietal foramina, craniofacial dysostosis, and mental retardation, caused by deletions in the short arm of chromosome 11. Am J Hum Genet. 1996; 58(4): 734-742, indexed in Pubmed: 8644736.

2. Boyd GI. The emissary foramina of the cranium in man and the anthropoids. J Anat. 1930; 65(Pt 1): 108-121, indexed in Pubmed: 17104299.

3. Carolineberry A, Berry RJ. Epigenetic variation in the human cranium. J Anat. 1967; 101 (Pt 2): 361-379, indexed in Pubmed: 4227311.

4. Chapot R, Saint-Maurice JP, Narata AP, et al. Transcranial puncture through the parietal and mastoid foramina for the treatment of dural fistulas. Report of four cases. J Neurosurg. 2007; 106(5): 912-915, doi: 10.3171/ jns.2007.106.5.912, indexed in Pubmed: 17542540.

5. de Souza Ferreira MR, Galvão AP, de Queiroz Lima PT, et al. The parietal foramen anatomy: studies using dry skulls, cadaver and in vivo MRI. Surg Radiol Anat. 2021; 43(7): 1159-1168, doi: 10.1007/s00276-020-02650-0, indexed in Pubmed: 33399919.

6. Durão C, Carpinteiro D, Pedrosa F, et al. Enlarged parietal foramina: a rare forensic autopsy finding. Int J Legal Med. 2016; 130(3): 855-857, doi: 10.1007/s00414-015-1239-6, indexed in Pubmed: 26233611.

7. Gangmei G, Devi HS, Daimei T, et al. Variations of parietal foramen in dried adult human skulls. ISOR J Dent Med Sci. 2018; 17(5): 26-29.

8. Griessenauer CJ, Veith P, Mortazavi MM, et al. Enlarged parietal foramina: a review of genetics, prognosis, radiology, and treatment. Childs Nerv Syst. 2013; 29(4): 543-547, doi: 10.1007/s00381-012-1982-7, indexed in Pubmed: 23207976. 
9. Keskil S, Gözil R, Çalgüner E. Common surgical pitfalls in the skull. Surg Neurol. 2003; 59(3): 228-231, doi: 10.1016/ s0090-3019(02)01038-8.

10. Lacković Z, Filipović B, Matak I, et al. Activity of botulinum toxin type $A$ in cranial dura: implications for treatment of migraine and other headaches. Br J Pharmacol. 2016; 173(2): 279-291, doi: 10.1111/bph.13366, indexed in Pubmed: 26493010.

11. Louis RG, Loukas M, Wartmann CT, et al. Clinical anatomy of the mastoid and occipital emissary veins in a large series. Surg Radiol Anat. 2009; 31(2): 139-144, doi: 10.1007/ s00276-008-0423-5, indexed in Pubmed: 18974919.

12. Makandar UK, Kulkarni PR, Suryakar AN. Comparative Study of Incidence of Parietal Foramina in North and South Indian Human Crania. Indian J Foren Med Toxicol. 2013; 7(2): 123, doi: 10.5958/j.0973-9130.7.2.027.

13. Mann RW. Enlarged parietal foramina and craniosynostosis in an American Indian child. Am J Roentgenol. 1990; 154(3): 658, doi: 10.2214/ajr.154.3.2106245, indexed in Pubmed: 2106245.

14. Mann R, Manabe J, Byrd J. Relationship of the parietal foramen and complexity of the human sagittal suture. Int J Morphol. 2009; 27(2), doi: 10.4067/s071795022009000200040

15. Mavrogiannis LA, Taylor IB, Davies SJ, et al. Enlarged parietal foramina caused by mutations in the homeobox genes ALX4 and MSX2: from genotype to phenotype. Eur J Hum Genet. 2006; 14(2): 151-158, doi: 10.1038/ sj.ejhg.5201526, indexed in Pubmed: 16319823.

16. Mortazavi MM, Tubbs RS, Riech S, et al. Anatomy and pathology of the cranial emissary veins: a review with surgical implications. Neurosurgery. 2012; 70(5): 1312-1318, doi: 10.1227/ NEU.0b013e31824388f8, indexed in Pubmed: 22127046.

17. Mupparapu M, Binder RE, Duarte F. Hereditary cranium bifidum persisting as enlarged parietal foramina (Catlin marks) on cephalometric radiographs. Am J Orthod Dentofacial Orthop. 2006; 129(6): 825-828, doi: 10.1016/j. ajodo.2006.02.020, indexed in Pubmed: 16769502.

18. Murlimanju BV, Reddy G, Prabhu LV, et al. Foramen of vesalius: prevalence, morphology, embryological basis and clinical implications. J Surg Acad. 2015; 5(1): 24-28.

19. Murlimanju BV, Saralaya VV, Somesh MS, et al. Morphology and topography of the parietal emissary foramina in South Indians: an anatomical study. Anat Cell Biol. 2015; 48(4): 292-298, doi: 10.5115/acb.2015.48.4.292, indexed in Pubmed: 26770881.

20. O'Rahilly R, Twohig MJ. Foramina parietalia permagna. Am J Roentgenol Radium Ther Nucl Med. 1952; 67(4): 551-561, indexed in Pubmed: 14914930.
21. Reddy AT, Hedlund GL, Percy AK. Enlarged parietal foramina: association with cerebral venous and cortical anomalies. Neurology. 2000; 54(5): 1175-1178, doi: 10.1212/ wnl.54.5.1175, indexed in Pubmed: 10720293.

22. Reis CVC, Deshmukh V, Zabramski JM, et al. Anatomy of the mastoid emissary vein and venous system of the posterior neck region: neurosurgical implications. Neurosurgery. 2007; 61(5 Suppl 2): 193-200; doi: 10.1227/01. neu.0000303217.53607.d9, indexed in Pubmed: 18091233.

23. Sharma NA, Garud RS. Morphometric evaluation and a report on the aberrations of the foramina in the intermediate region of the human cranial base: a study of an Indian population. Eur J Anat. 2011; 15(3): 140-149.

24. Singh $D$, Raibagkar $D$. Study of variation in atypical foramina of dry human skull. NJIRM. 2011; 2(2): 1-5.

25. Thompson EM, Baraitser M, Hayward RD. Parietal foramina in Saethre-Chotzen syndrome. J Med Genet. 1984; 21(5): 369-372, doi: 10.1136/jmg.21.5.369, indexed in Pubmed: 6502651.

26. Tsutsumi S, Nonaka S, Ono $\mathrm{H}$, et al. The extracranial to intracranial anastomotic channel through the parietal foramen: delineation with magnetic resonance imaging. Surg Radiol Anat. 2016; 38(4): 455-459, doi: 10.1007/ s00276-015-1579-4, indexed in Pubmed: 26498934.

27. Tubbs R, Doughty K, Oakes W, et al. Duane's syndrome and giant parietal foramina. Pediatr Neurol. 2004; 30(1): 75-76, doi: 10.1016/s0887-8994(03)00425-9.

28. Tubbs RS, Smyth MD, Oakes WJ. Parietal foramina are not synonymous with giant parietal foramina. Pediatr Neurosurg. 2003; 39(4): 216-217, doi: 10.1159/000072475, indexed in Pubmed: 12944704.

29. Wilkie AO, Tang Z, Elanko N, et al. Functional haploinsufficiency of the human homeobox gene MSX2 causes defects in skull ossification. Nat Genet. 2000; 24(4): 387-390, doi: 10.1038/74224, indexed in Pubmed: 10742103.

30. Wuyts W, Cleiren E, Homfray T, et al. The ALX4 homeobox gene is mutated in patients with ossification defects of the skull (foramina parietalia permagna, OMIM 168500). J Med Genet. 2000; 37(12): 916-920, doi: 10.1136/ jmg.37.12.916, indexed in Pubmed: 11106354.

31. Wysocki J, Reymond J, Skarzyński H, et al. The size of selected human skull foramina in relation to skull capacity. Folia Morphol. 2006; 65(4): 301-308, indexed in Pubmed: 17171609

32. Yoshioka N, Rhoton AL, Abe H. Scalp to meningeal arterial anastomosis in the parietal foramen. Neurosurgery. 2006; 58(1 Suppl): ONS123-6; discussion ONS123, doi: 10.1227/01. NEU.0000193516.46104.27, indexed in Pubmed: 16543869. 